\title{
Support for policy options to increase vaccination coverage in British Columbia, Canada: an electronic survey
}

\author{
Julie A. Bettinger PhD MPH, Devon Greyson PhD MLIS, Richard Carpiano PhD MPH, \\ Pamela de Bruin RN MPH, Issy Aguiar BSN RN, Monika Naus MD, Brett Hodson MSc
}

\section{Abstract}

Background: Motivated by concerns of inadequate vaccination coverage and the potential for outbreaks of vaccine-preventable diseases, Canadian provinces have been discussing, implementing and tightening policies requiring documentation of vaccination for school enrolment. We sought to understand the acceptability of 14 potential vaccination policy levers among parents and other adults in British Columbia.

Methods: A representative online panel of 1308 adults in BC was surveyed in April 2017. Respondents were representative of the $\mathrm{BC}$ population by sex, age, geographic residence and percentage of household with children younger than 19 years. We used Poisson regression to estimate predictors of policy endorsement.

Results: Most respondents (> $80 \%$ ) held positive attitudes toward vaccination. Policies such as mandatory documentation of vaccination at school entry were supported by more than $75 \%$ of all respondents. Punitive policies, such as denial of child tax benefits for nonvaccination, were supported by less than $40 \%$ of respondents. In multivariable regression, respondents with positive attitudes toward vaccination were significantly more likely to strongly support all potential policies. Additionally, female respondents and respondents with postsecondary education were significantly more likely to strongly support policies involving additional requirements for parents.

Interpretation: Most adults in BC held favourable attitudes toward vaccination, and strong support existed for policies designed to support vaccination. This study provides evidence that most adults in BC are supportive of vaccination and, when presented with a wide range of options, would likely be supportive of information and requirement policy options designed to increase vaccination uptake.

anada has limited vaccination requirements for school entry. Only 2 of Canada's 10 provinces Ontario and New Brunswick - currently have laws requiring proof of vaccination, and both allow exemptions for medical reasons and for philosophical or religious beliefs. ${ }^{1,2}$ However, owing to increasing concern regarding outbreaks of vaccine-preventable diseases, school-based interventions to increase vaccination of children have received renewed attention. ${ }^{3}$ For example, in Ontario, the longstanding Immunization of School Pupils Act ${ }^{1}$ was amended such that, beginning in 2014, parents or guardians were required to provide proof of vaccination against 9 diseases or were required to file exemptions. In December 2015, Ontario launched multiple initiatives regarding communication, knowledge translation and strengthening the implementation of legislative mandates, ${ }^{4}$ and, in 2017, required that parents seeking nonmedical exemptions for their children complete an educational session on vaccine evidence. ${ }^{5}$ However, recent efforts to address decreasing vaccination coverage in some other provinces have encountered resistance. In 2017, the Alberta government declined to adopt a policy of mandatory vaccination for students, ${ }^{6}$ and in 2018, the Manitoba School Boards Association voted against a motion to lobby the provincial government to adopt stricter school-entry vaccination requirements. ${ }^{7,8}$

Currently, British Columbia does not require vaccination or even documentation of vaccination for school entry, although that may be changing. ${ }^{9}$ Vaccination records of school children are collected under a voluntary scheme at school entry, especially at kindergarten age, with more

Competing interests: None declared.

This article has been peer reviewed.

Correspondence to: Julie Bettinger, jbettinger@ bcchr.ubc.ca

CMAJ Open 2019. DOI:10.9778/cmajo.20190034 
variability in such collection when children enter school at older ages. Public health staff members are authorized to request student records from the school under both the School $A c t^{10}$ and under the Independent School Regulation ${ }^{11}$ for the purpose of planning delivery of health services to students. As coverage rates in $\mathrm{BC}$ children are below national averages for many vaccines, ${ }^{12,13}$ a better understanding of the acceptability of potential policy levers could provide valuable assistance to policy-makers as they search for methods to increase vaccination rates. The objectives of this study were to assess the level of support in $\mathrm{BC}$ in the general population and in parents for a range of policy options designed to increase vaccination rates and to determine the characteristics associated with strong support.

\section{Methods}

\section{Sample and procedures}

An existing online panel of BC adults was surveyed Apr. 3-14, 2017. We recruited participants by email through the Sentis online consumer research panel. The sample was constructed to match the population distribution by age, sex and households with children younger than 19 years in each of the 5 regional health authorities. Because we were interested in the attitudes of parents of school-aged children, we also oversampled parents of children younger than 19 years to ensure adequate responses for parental questions.

Respondents received an email invitation with a survey link and provided informed consent before proceeding to the survey. A reminder email was sent 3 days after the initial email. Respondents earned points redeemable for retailer gift cards from the panel provider. The panel provider had no input on the study design, analysis or manuscript.

\section{Survey design and development}

Our online survey instrument consisted of 24 items pertaining to the topical domains described in the Measures section, as well as demographic questions. The instrument was pilot tested to ensure questions and response options were clear to respondents. A copy of the survey is available on request.

\section{Measures}

Support for vaccination policy levers was measured with 14 items assessing support for national and international laws and public proposals ${ }^{14-16}$ that had been validated in a previous study. ${ }^{16}$ We classified the policy options into 4 categories (Box 1). The 4-point response scale for these items ranged from 1 (strongly agree) to 4 (strongly disagree), which we recoded in reverse direction to reflect stronger endorsement in our models.

Demographic characteristics included sex, age, number of children younger than 19 years in the household, foreign born (v. Canadian born), education level and household income.

Vaccination-related practices consisted of 3 binary (yes/no) items asking respondents whether they had ever delayed or ever refused a vaccine for their child (asked of parents), and ever refused a vaccine for themselves (asked of parents and nonparents).

\section{Box 1: Categorization of policy options}

\section{Information or service provision}

- The government should invest more money in research to ensure that vaccines are safe.

- Parents need access to more information about childhood vaccinations.

- School vaccination rates should be made public.

- More child vaccination-related services should exist.

\section{Requirements}

- At school entry, all parents should be required to provide records showing whether their child has been vaccinated.

- Parents who refuse vaccinations for their children should be required to sign a vaccine refusal form.

- $\quad$ Parents who refuse vaccinations for their children should be required to attend an education session.

- $\quad$ Children should not be allowed to attend public schools without all age-recommended vaccinations without a documented medical reason for not being vaccinated.

\section{Penalties}

- Parents should be denied their monthly Canada child tax benefit until their children receive all age-recommended vaccinations.

- Parents who lose their jobs should be denied unemployment benefits until their children receive all agerecommended vaccinations.

- $\quad$ Parents should be required to pay a special tax or fine if their children have not received all age-recommended vaccinations.

- Doctors should be allowed to refuse to see families who choose not to vaccinate their children.

\section{Rewards}

- Parents should receive a financial reward if their children have received all age-recommended vaccinations.

- Parents should receive a special tax break or credit if their children have received all age-recommended vaccinations.

Normative influences consisted of 2 items assessing whether the respondent had received negative information about vaccines from a) family members and b) friends. ${ }^{17,18}$

Attitudes toward vaccines consisted of 5 items based on the theory of planned behaviour that assessed the respondents' attitudes toward vaccines. ${ }^{17-19}$ Each item was coded on a 4-point scale ranging from 1 (strongly agree) to 4 (strongly disagree).

\section{Statistical analysis}

The total sample was weighted for households with children younger than 19 years because we oversampled parents of children younger than 19 years of age using the 2016 Canadian Census. SAS version 9.2 was used for all analyses. We present descriptive data via weighted percentages for the total sample.

Our analyses consisted of 2 steps. First, we computed descriptive statistics for the study variables across 2 groups: total respondents and parents with children younger than 19 years. Second, we used Poisson regression with robust 
variance $^{20}$ to estimate predictors of policy endorsement for those who strongly agreed with policies (v. all other responses). We selected this cut-off because it represented the highest degree of endorsement. The demographic, behavioural, normative and attitudinal characteristics described above were examined to determine whether specific policies were more or less likely to appeal to specific population groups. For these models, the 5 questions about vaccine attitude had high internal consistency (Cronbach $\alpha=0.93$ ) and thus were combined into a mean composite measure for vaccine attitudes and reverse coded for ease of understanding (ranging from 1 [strongly disagree] to 4 [strongly agree]). The variables of vaccination-related practices pertaining to whether respondents had every delayed or refused vaccines for their child were combined into one variable with 3 levels: 1) parents who had delayed or refused; 2) parents who had not delayed or refused; and 3) nonparents. Any characteristic with a prevalence ratio above 1 and a $p$ value of 0.05 or less in the multivariable model indicated the characteristic was associated with strong support for the policy, with the prevalence ratio indicating the percent increase (if $>1$ ) or decease (if $<1$ ) in the probability of support for the policy for a characteristic of interest compared with its referent or each unit change in the vaccine attitude scale.

\section{Ethics approval}

The University of British Columbia provided research ethics approval.

\section{Results}

A total of 1352 invitations were sent, and 1002 adults (aged $\geq 19 \mathrm{yr}$ ) responded (74\% response rate), with an additional 306 parents enrolled for a total sample size of 1308. Demographic characteristics of the respondents are shown in Table 1 . In both the total and the subset of parents with young children, just over half were female $(55.2 \%$ and $56.6 \%$, respectively), $79.2 \%$ were born in Canada and $76.0 \%$ had education beyond secondary school. A total of $41.5 \%$ (weighted) had no children. Parent respondents were younger and had slightly higher household incomes than total respondents.

\section{Vaccination practices, normative influences and attitudes}

Vaccination practices and normative influences (friends and family) are shown in Table 1. Comparing parents of children younger than 19 years of age (henceforth termed "parents of young children") with parents of older children or respondents without children, more parents of young children reported knowing friends or family members who had refused vaccines. Vaccine attitudes among the total participants and parents of young children are shown in Figure 1 (the full survey results are available in Appendix 1, www.cmajopen.ca/content/7/2/ E264/suppl/DC1). The mean of the vaccine-attitudes composite measure on a 4.0 scale was 3.37 (standard deviation [SD] 0.61 ) for the total sample and 3.30 (SD 0.62) for parents of young children.
Table 1: Characteristics of 1308 adults in British Columbia surveyed in April 2017 to assess support for potential vaccination policy levers

\begin{tabular}{|c|c|c|}
\hline \multirow[b]{2}{*}{ Characteristic } & \multicolumn{2}{|l|}{ No. (\%) } \\
\hline & $\begin{array}{c}\text { Parents with children } \\
\text { aged }<19 \mathrm{yr} \\
n=587\end{array}$ & $\begin{array}{c}\text { Total }^{*} \\
n=1308\end{array}$ \\
\hline Sex, female & $332(56.6)$ & $726(55.2)$ \\
\hline \multicolumn{3}{|l|}{ Age, yr } \\
\hline $18-24$ & $17(2.9)$ & $63(5.4)$ \\
\hline $25-34$ & $171(29.1)$ & $301(21.2)$ \\
\hline $35-44$ & $180(30.7)$ & $251(15.7)$ \\
\hline $45-54$ & $135(23.0)$ & $259(18.8)$ \\
\hline $55-64$ & $70(11.9)$ & $220(18.3)$ \\
\hline$\geq 65$ & $14(2.4)$ & $214(20.6)$ \\
\hline Children aged < $19 \mathrm{yr}$ & $587(100)$ & $587(28.2)$ \\
\hline Foreign born & $125(21.3)$ & $274(20.8)$ \\
\hline \multicolumn{3}{|l|}{ Education level } \\
\hline$\leq$ Secondary/high school & $121(20.6)$ & $303(24.0)$ \\
\hline $\begin{array}{l}\text { College/trade/technical } \\
\text { degree }\end{array}$ & $228(38.8)$ & $494(37.4)$ \\
\hline$\geq$ University degree & $233(39.7)$ & $496(37.4)$ \\
\hline Prefer not to answer & $5(0.9)$ & $15(1.2)$ \\
\hline \multicolumn{3}{|l|}{ Annual household income, \$ } \\
\hline$<35000$ & $59(10.1)$ & $174(14.3)$ \\
\hline $35000-74999$ & $150(25.6)$ & $390(31.1)$ \\
\hline $75000-99999$ & $140(23.9)$ & $258(18.5)$ \\
\hline$\geq 10000$ & $185(31.5)$ & $333(23.5)$ \\
\hline Prefer not to answer & $53(9.0)$ & $153(12.5)$ \\
\hline \multicolumn{3}{|l|}{ Vaccination practices } \\
\hline $\begin{array}{l}\text { Delayed or refused } \\
\text { vaccine for child }\end{array}$ & $153(26.1)$ & $172(19.2 \dagger)$ \\
\hline Refused for self & $118(20.1)$ & 255 (19.3) \\
\hline \multicolumn{3}{|l|}{ Normative influences } \\
\hline $\begin{array}{l}\text { Family member refused } \\
\text { for self }\end{array}$ & $124(21.1)$ & $258(19.3)$ \\
\hline $\begin{array}{l}\text { Family member delayed } \\
\text { or refused for child }\end{array}$ & $138(23.5)$ & $242(17.0)$ \\
\hline Friend refused for self & $184(31.4)$ & $378(28.2)$ \\
\hline $\begin{array}{l}\text { Friend delayed or } \\
\text { refused for child }\end{array}$ & $254(43.3)$ & $427(29.4)$ \\
\hline $\begin{array}{l}\text { Heard negative vaccine } \\
\text { information }\end{array}$ & $447(76.1)$ & $987(75.2)$ \\
\hline From family & $122(20.8)$ & $235(17.1)$ \\
\hline From friends & $209(35.6)$ & $450(4.0)$ \\
\hline
\end{tabular}

*Population percentages for the total are weighted for households with children younger than 19 years.

†Percentage based on respondents with children $(n=892)$. 


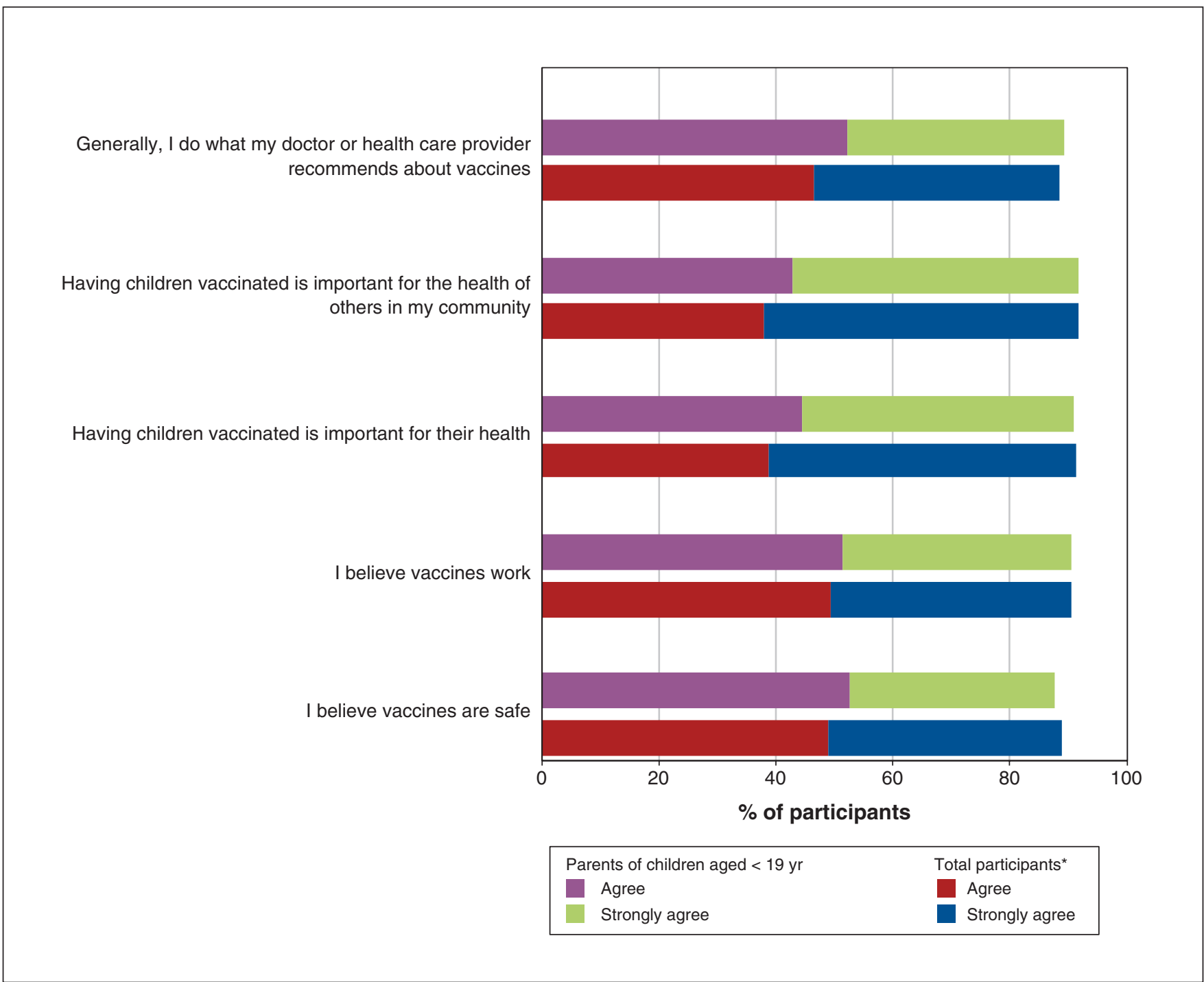

Figure 1: Proportion of respondents who agreed with positive vaccine statements. *Population percentages for the total are weighted for households with children younger than 19 years.

\section{Support for vaccination policies}

Figure 2 shows the proportion of respondents who either agreed or strongly agreed with 14 specific vaccination policies (the full survey results are available in Appendix 2, www.cmajopen.ca/content/7/2/E264/suppl/DC1). Policies pertaining to information and services received the highest level of agreement from all respondents as well as parents of young children. Policies that establish additional requirements for parents received agreement from most survey respondents, including both parents and nonparents. Rewards, or policies that provided incentives to vaccinating parents, were supported by more than half of parents of young children but received less support among total respondents $(p<0.005)$. Finally, penalties were supported by a minority of respondents, regardless of parental status, with particularly low support for the denial of unemployment benefits to nonvaccinating parents.
Multivariable analyses of vaccination-policy support

Tables 2 and 3 show the adjusted prevalence ratios obtained from multivariable models regressing the demographic, behavioural, normative and attitudinal characteristics on strong support for each policy.

Demographic factors, in general, showed inconsistent associations across policies. However, some patterns existed. Women were significantly more likely to endorse support for information and services, and requirement policies (e.g., vaccine record provision [prevalence ratio 1.21], signed refusal [prevalence ratio 1.23] and education sessions [prevalence ratio 1.24]). Younger participants were significantly more likely to support some penalties (denying unemployment benefits [prevalence ratio 2.81 for the age group 18-24 yr, and 2.03 for the age group 25-34 yr], and applying taxes or fines [prevalence ratio 1.83 for the age group 25-34 yr, and 1.63 for the age group 35-44 yr) and reward policies, and parents of young 


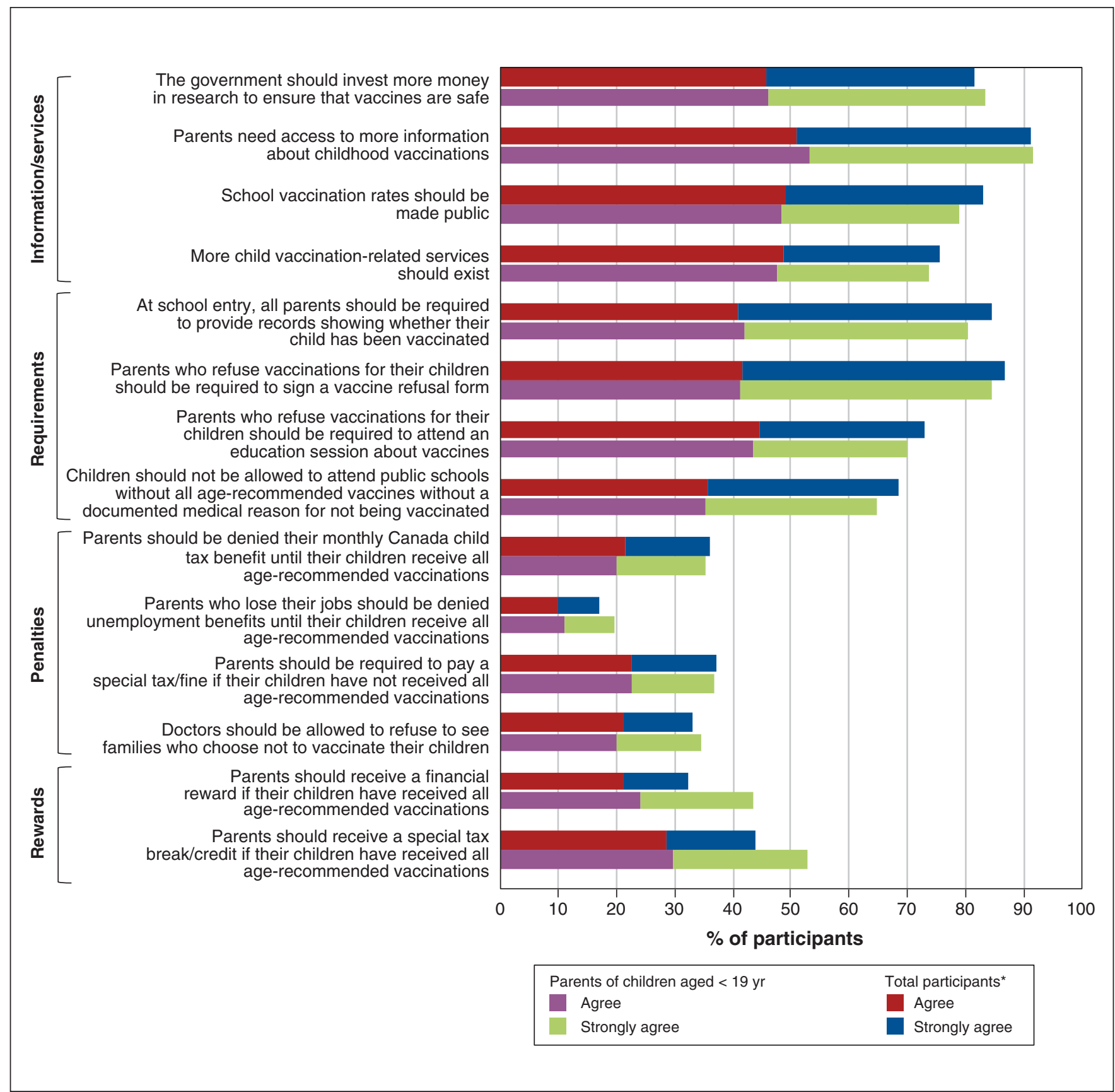

Figure 2: Proportion of respondents who agreed with 14 vaccination policies. *Population percentages for the total are weighted for households with children younger than 19 years.

children were significantly more likely to support reward policies. Lower income was associated with support for information and services (e.g., research funding [prevalence ratio 1.43] and more vaccination services [prevalence ratio 1.40]), and participants with higher education (e.g., beyond secondary) had a significantly higher likelihood of supporting policies of school vaccination rates being made public (prevalence ratio 1.42), parents being required to provide vaccination records (prevalence ratio 1.25) and signed refusals (prevalence ratio 1.23), doctors' refusing unvaccinated patients (prevalence ratio 1.66), school bans of unvaccinated students (prevalence ratio 1.22) and denial of child tax benefits (prevalence ratio 2.00).

Regarding vaccination practices, normative influences and vaccine attitudes, having positive vaccine attitudes was the only covariate predictive of support for 13 out of 14 policies. No behavioural or normative influence was consistently associated with policy support (or nonsupport). However, having normative influences that delayed or refused vaccines, or having been provided negative information about vaccines, did predict greater support for policies pertaining to information 


\begin{tabular}{|c|c|c|c|c|c|c|c|c|}
\hline \multirow[b]{2}{*}{ Characteristic } & \multicolumn{4}{|c|}{ Information and services } & \multicolumn{4}{|c|}{ Requirements } \\
\hline & $\begin{array}{c}\text { More } \\
\text { government- } \\
\text { funded } \\
\text { research } \\
n=1308\end{array}$ & $\begin{array}{c}\text { More } \\
\text { information } \\
\text { access } \\
n=1300\end{array}$ & $\begin{array}{l}\text { More } \\
\text { vaccination } \\
\text { services } \\
n=1304\end{array}$ & $\begin{array}{l}\text { School } \\
\text { coverage } \\
\text { rates public } \\
n=1289\end{array}$ & $\begin{array}{c}\text { Parents } \\
\text { provide } \\
\text { vaccination } \\
\text { records } \\
n=1285\end{array}$ & $\begin{array}{l}\text { Parents } \\
\text { provide } \\
\text { signed } \\
\text { refusal } \\
n=1285\end{array}$ & $\begin{array}{c}\text { Parent } \\
\text { education } \\
\text { sessions } \\
n=1300\end{array}$ & $\begin{array}{c}\text { Ban from } \\
\text { school } \\
n=1289\end{array}$ \\
\hline Sex, female & NS & $1.18 \ddagger$ & NS & NS & $1.21 \S$ & $1.23 \S$ & $1.24 \S$ & NS \\
\hline Foreign born & $1.34 \S$ & NS & NS & NS & NS & NS & NS & $0.80 \ddagger$ \\
\hline \multicolumn{9}{|l|}{ Annual household income, \$ } \\
\hline$\geq 100000$ & Ref. & NS & Ref. & NS & NS & NS & NS & NS \\
\hline 75 000-99999 & 1.18 & NS & 0.99 & NS & NS & NS & NS & NS \\
\hline $35000-74999$ & $1.38 \S$ & NS & $1.37 \S$ & NS & NS & NS & NS & NS \\
\hline$<35000$ & $1.43 \S$ & NS & $1.40 \ddagger$ & NS & NS & NS & NS & NS \\
\hline \multicolumn{9}{|l|}{ Education level } \\
\hline $\begin{array}{l}\leq \text { Secondary/ } \\
\text { high school }\end{array}$ & NS & NS & NS & Ref. & Ref. & Ref. & NS & Ref. \\
\hline $\begin{array}{l}\text { College/trade/ } \\
\text { technical degree }\end{array}$ & NS & NS & NS & 1.23 & $1.22 \S$ & 1.11 & NS & $1.22 \ddagger$ \\
\hline$\geq$ University degree & NS & NS & NS & $1.42 \S$ & $1.25 \S$ & $1.23 \S$ & NS & 1.19 \\
\hline $\begin{array}{l}\text { Positive vaccine attitudes } \\
\text { (composite measure) }\end{array}$ & NS & $1.42 \emptyset$ & $4.81 \rrbracket$ & 3.479 & 3.679 & $2.52 ף$ & 3.919 & 4.92ף \\
\hline $\begin{array}{l}\text { Delayed or refused vaccine } \\
\text { for child } †\end{array}$ & $1.24 \ddagger$ & $1.33 \S$ & NS & NS & NS & $0.78 \ddagger$ & NS & NS \\
\hline $\begin{array}{l}\text { Refused vaccine for } \\
\text { themselves }\end{array}$ & $1.39 \rrbracket$ & $1.37 \S$ & NS & NS & NS & NS & NS & $1.40 \S$ \\
\hline $\begin{array}{l}\text { Friend delayed or refused } \\
\text { vaccine for child }\end{array}$ & NS & $1.22 \S$ & NS & NS & NS & NS & NS & NS \\
\hline $\begin{array}{l}\text { Family member delayed or } \\
\text { refused vaccine for } \\
\text { themselves }\end{array}$ & NS & NS & NS & $1.34 \S$ & NS & NS & NS & NS \\
\hline $\begin{array}{l}\text { Friend delayed or refused } \\
\text { vaccine for themselves }\end{array}$ & NS & NS & $1.25 \S$ & NS & NS & NS & NS & NS \\
\hline $\begin{array}{l}\text { Negative information about } \\
\text { vaccines from family }\end{array}$ & $1.22 \S$ & NS & NS & NS & NS & NS & NS & NS \\
\hline \multicolumn{9}{|c|}{ 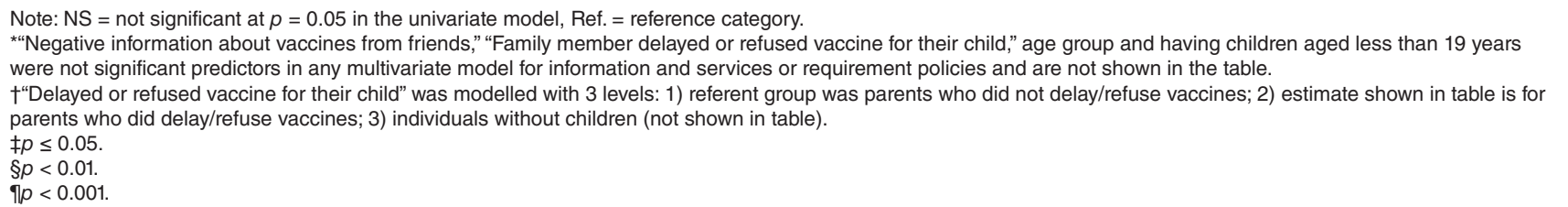 } \\
\hline
\end{tabular}

and services. Parents who had delayed or refused vaccines for their child did not support requiring signed vaccine refusal forms (prevalence ratio 0.78).

In terms of the predictors associated with the different policy categories, policies pertaining to information and services varied in terms of predictors associated with strong support, with positive vaccination attitudes being the only common covariate associated with strong support across all but 1 of these policies. This category of policy was the only one to receive strong support from respondents who had delayed or refused vaccines for their children (prevalence ratio 1.24 for more government-funded research, and 1.33 for more information access). In general, requirement policies were more strongly supported by women, participants with postsecondary education and participants with positive attitudes toward vaccination. Penalty policies were strongly supported by participants with positive vaccination attitudes, men, participants with higher incomes and those in younger age groups. Importantly, several population groups, such as women and immigrants, were significantly less likely to support penalty 


\begin{tabular}{|c|c|c|c|c|c|c|}
\hline \multirow[b]{2}{*}{ Characteristic } & \multicolumn{4}{|c|}{ Penalties } & \multicolumn{2}{|c|}{ Rewards } \\
\hline & $\begin{array}{c}\text { Deny child } \\
\text { tax benefit } \\
n=1285\end{array}$ & $\begin{array}{c}\text { Deny } \\
\text { unemployment } \\
\text { benefits } \\
n=1300\end{array}$ & $\begin{array}{l}\text { Tax or } \\
\text { fine } \\
n=1304\end{array}$ & $\begin{array}{l}\text { Allow doctors to } \\
\text { refuse } \\
\text { unvaccinated } \\
\text { patients } \\
n=1289\end{array}$ & $\begin{array}{c}\text { Special tax } \\
\text { break or } \\
\text { credit } \\
n=1304\end{array}$ & $\begin{array}{c}\text { Financial } \\
\text { reward } \\
n=1304\end{array}$ \\
\hline Sex, female & $0.68 \dagger$ & $0.61 \dagger$ & NS & NS & NS & NS \\
\hline \multicolumn{7}{|l|}{ Age, yr } \\
\hline $18-24$ & NS & $2.81 \dagger$ & 1.70 & $3.26 \dagger$ & $2.20 \ddagger$ & $5.26 \dagger$ \\
\hline $25-34$ & NS & $2.03 \ddagger$ & $1.83+$ & $3.22 \S$ & $2.06+$ & $4.57 \dagger$ \\
\hline $35-44$ & NS & 1.74 & $1.63 \ddagger$ & $2.62 \dagger$ & 1.36 & $2.73 \dagger$ \\
\hline $45-54$ & NS & 1.48 & 1.48 & $1.93 \ddagger$ & 1.06 & $2.26 \ddagger$ \\
\hline $55-64$ & NS & 1.31 & 1.33 & $2.12 \ddagger$ & 0.73 & 1.15 \\
\hline$\geq 65$ & NS & Ref. & Ref. & Ref. & Ref. & Ref. \\
\hline Children aged $<19 \mathrm{yr}$ & NS & NS & NS & NS & $1.75 \S$ & $1.97 \dagger$ \\
\hline Foreign born & NS & NS & NS & NS & NS & $1.60 \dagger$ \\
\hline \multicolumn{7}{|l|}{ Education level } \\
\hline$\leq$ Secondary/high school & Ref. & NS & NS & Ref. & NS & NS \\
\hline College/trade/technical degree & $1.65 \dagger$ & NS & NS & $1.99 \dagger$ & NS & NS \\
\hline$\geq$ University degree & $2.00 \dagger$ & NS & NS & $1.66 \ddagger$ & NS & NS \\
\hline $\begin{array}{l}\text { Positive vaccine attitudes (composite } \\
\text { measure) }\end{array}$ & $5.73 \S$ & $6.48 \S$ & $8.26 \S$ & $6.63 \S$ & $2.73 \S$ & $2.81 \S$ \\
\hline \multicolumn{7}{|c|}{ 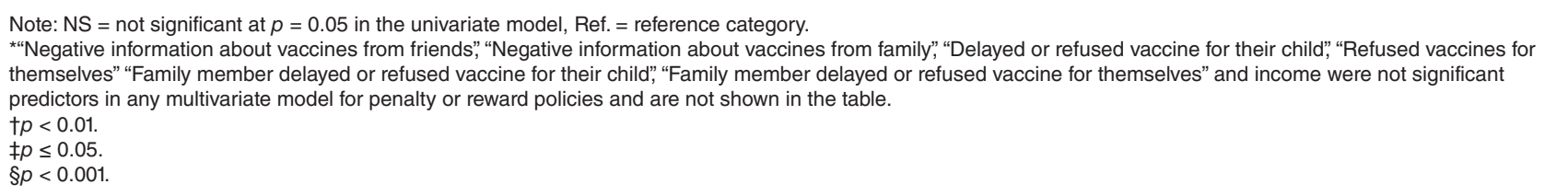 } \\
\hline
\end{tabular}

policies. Finally, rewards were most strongly supported by those in younger age groups (i.e., of child-bearing age) and those with young children.

\section{Interpretation}

This study examines the support for a variety of vaccination policy options and identifies the factors associated with this support. Overall, these findings indicate that vaccination is a strongly supported social norm among our sample of BC adults, and that several nonpunitive policies might be well accepted. British Columbians expect parents to vaccinate their children, and for most policies, support is similar among parents and the general public - with the exception of greater support among parents for policies that directly benefit these parents (i.e., financial rewards or tax breaks). Depending on the policy, successful implementation may require special attention (e.g., communication and logistical assistance) be paid to specific populations to facilitate acceptance. Some populations, such as those who do not support vaccination or who do not have strong attitudes in support of vaccines, may be unlikely to agree with any measures directly affecting them.
Public support is important for the success of vaccination policy to minimize risks of unintended consequences from population backlash. Moreover, public attitudes toward such policies can vary substantially depending on context. For example, whereas California's recent revision of their school vaccination law (allowing only medical exemptions in public schools) appears to have been well-received by the majority, Italy has experienced substantial backlash to recent tightening of childhood vaccine policy (requiring more vaccines and imposing financial penalties). ${ }^{21,22}$ In our study, policies involving additional requirements for parents garnered support from most respondents, which was similar to the support seen in California, where $67 \%$ of adults and $65 \%$ of parents of public school children felt that children who have not been vaccinated should not be allowed to attend school. ${ }^{23}$ By contrast, more punitive policies, such as denial of child tax benefits or other government benefits or services - similar to the "no jab, no pay" policy ${ }^{14,24,25}$ in Australia - were not viewed favourably in our study. Less than $15 \%$ of respondents indicated strong support, and important population groups, such as women and immigrants, indicated strong disagreement. Implementation of an unpopular policy could potentially 
undermine attempts to increase vaccine coverage, as has been seen in Italy and other jurisdictions. ${ }^{22,26}$

\section{Limitations}

These findings need to be considered with respect to some limitations. First, our data are from a nonprobability online panel. Using a volunteer sample may introduce selection bias, as those who participate may be different from nonparticipants. Nevertheless, our sample was representative of the BC population by geography, sex, age and proportion of households with children. The proportion in our survey who delayed or refused vaccines (26\%) for their child was similar to population rates at $30 \%$ of 7 -year-old children in BC. ${ }^{12}$

\section{Conclusion}

This study provides evidence that most BC adults are supportive of vaccination and would likely be supportive of nonpunitive policy options designed to increase uptake of vaccines. Similar context-specific research conducted in other jurisdictions in Canada, the United States and beyond would benefit public discourse and government decision-making. This is especially true in locations where vaccination policy is hotly debated. Often in such settings, debate is fueled by anecdote in media stories or, at best, public surveys containing 1 or 2 items about vaccinations that offer limited information for such a nuanced issue. Furthermore, governments would benefit from future research focusing on the extent to which such policy attitudes might remain stable over time, including before and after introduction of a particular policy, and even compared and contrasted with attitudes in other provinces or jurisdictions.

\section{References}

1. R.R.O. 1990, Regulation 645: General. Immunization of School Pupils Act: Ontario Ministry of Health and Long-Term Care; updated 2018 Mar. 29.

2. Public Health Act, SNB 1998, c P-22.4.

3. Carman T, Kirkey S. Should proof of vaccinations be required for school entry in B.C.? Vancouver Sun 2015 Aug. 26, 2015. Available: www.vancouversun.com/ health/Should+proof+vaccinations+required+school+entry/11319594/story.html (accessed 2018 July 3).

4. Immunization 2020: modernizing Ontario's publicly funded immunization program. Toronto: Ontario Ministry of Health and Long-Term Care; 2015. Available: www.health.gov.on.ca/en/common/ministry/publications/reports/ immunization_2020 (accessed 2017 Aug. 21).

5. The Protecting Patients Act, 2017 [news release]. Toronto: Ministry of Health and Long-Term Care; 2017 May 30. Available: https://news.ontario.ca/mohltc/ en/2017/05/the-protecting-patients-act-2017.html (accessed 2018 Oct. 26).

6. Kraus S. Alberta government not supporting mandatory vaccinations for students. Global News 2017 Apr. 19. Available: https://globalnews.ca/news /3390399/alberta-government-not-supporting-mandatory-vaccinations-for -students (accessed 2018 Oct. 26).

7. Glowacki L. Manitoba schools consider lobbying province to make vaccines mandatory. CBC News 2018 Mar. 14. Available: www.cbc.ca/news/canada/ manitoba/mandatory-vaccinations-manitoba-schools-lobby-government-1. 4576669 (accessed 2018 Aug. 15).

8. Malone KG. Manitoba school boards vote against push to have all school children vaccinated. CTV News 2018 Mar. 19. Available: www.ctvnews.ca/ health/manitoba-school-boards-vote-against-push-to-have-all-school-children -vaccinated-1.3848675 (accessed 2018 Aug. 14).

9. Harnett CE. Schools will require kids' immunization status by fall, B.C. health minister says. Times Colonist 2019 Feb. 26. Available: www.timescolonist.com/ news/local/schools-will-require-kids-immunization-status-by-fall-b-c-health -minister-says-1.23645544 (accessed 2019 Feb. 26).

10. School Act, RSBC 1996, c412, s91.

11. Independent School Act, SBC221/2016, September 2, 2017, s9.

12. Immunization uptake in children by the seventh birthday 2012-2018. Vancouver: BC Centre for Disease Control; 2018. Available: www.bccdc.ca/resource
-gallery/Documents/Statistics and Research/Statistics and Reports/ Immunization/Coverage/7yo Coverage Results.pdf (accessed 2019 Feb. 26).

13. Bettinger J, MacDonald S. Epidemiologic trends in vaccine-preventable diseases and immunization in Canada. In: Bramadat P, Guay M, Bettinger JA, et al., editors. Public bealth in the age of anxiety. Toronto: University of Toronto Press; 2017:p. 229-60.

14. Immunisation and health check requirements for family tax benefit: no jab, no pay - immunisation requirements. Department of Social Services, Australian Government; updated 2018 Sept. 5. Available: www.dss.gov.au/ our-responsibilities/families-and-children/benefits-payments/strengthening -immunisation-for-young-children (accessed 2018 Aug. 14).

15. Immunization regulations. Washington State Department of Health. Available: www.doh.wa.gov/CommunityandEnvironment/Schools/ Immunization/Regulations (accessed 2017 Aug. 21).

16. Carpiano RM, Fitz NS. Public attitudes toward child undervaccination: a randomized experiment on evaluations, stigmatizing orientations, and support for policies. Soc Sci Med 2017;185:127-36.

17. Childhood National Immunization Coverage Survey - 2015. Ottawa: Statistics Canada; updated 2017 Nov. 20. Available: www23.statcan.gc.ca/ imdb/p3Instr.pl? Function=assembleInstr\&a=1 \& \&lang=en\&Item_Id=249677 (accessed 2017 Aug. 21).

18. Larson HJ, Jarrett C, Schulz WS, et al.; SAGE Working Group on Vaccine Hesitancy. Measuring vaccine hesitancy: the development of a survey tool. Vaccine 2015;33:4165-75.

19. Ajzen I, Fishbein M. Understanding attitudes and predicting social behavior. 1st ed. Upper Saddle River (NJ): Prentice-Hall, Inc.; 1980.

20. Barros AJ, Hirakata VN. Alternatives for logistic regression in cross-sectional studies: an empirical comparison of models that directly estimate the prevalence ratio. BMC Med Res Methodol 2003;3:21.

21. Attwell K, Navin MC, Lopalco PL, et al. Recent vaccine mandates in the United States, Europe and Australia: a comparative study. Vaccine 2018;36:7377-84.

22. Paterlini M. Italy suspends mandatory vaccination of nursery children after Senate vote. BM7 2018;362:k3506.

23. Baldassare M, Bonner D, Kordus D, et al. PPIC statewide survey: Californians \& their government. San Francisco: Public Policy Institute of California; May 2015. Available: www.ppic.org/content/pubs/survey/S_515MBS.pdf (accessed 2017 Aug. 21).

24. What are immunisation requirements. Department of Social Services, Australian Government; updated 2018 July 30. Available: www.humanservices. gov.au/individuals/enablers/immunisation-requirements/35396 (accessed 2018 Aug. 14).

25. No jab no play, no jab no pay. Sydney (AU): National Centre for Immunisation Research and Surveillance; updated December 2018. Available: www.ncirs.edu. au/consumer-resources/no-jab-no-play-no-jab-no-pay-policies (accessed 2018 Aug. 14).

26. Olive JK, Hotez PJ, Damania A, et al. The state of the antivaccine movement in the United States: a focused examination of nonmedical exemptions in states and counties [published erratum in PLoS Med 2018; 15:e1002616]. PLoS Med 2018;15:e1002578.

Affiliations: Vaccine Evaluation Center (Bettinger, Greyson), Department of Pediatrics, BC Children's Hospital, University of British Columbia, Vancouver, BC; Department of Communication (Greyson), University of Massachusetts, Amherst, Mass.; School of Public Policy, Department of Sociology and Center for Healthy Communities (Carpiano), University of California, Riverside, Riverside, Calif.; Interior Health Authority BC (de Bruin, Aguiar), Kelowna, BC; Communicable Diseases and Immunization Service (Naus), BC Centre for Disease Control; School of Population and Public Health (Naus), University of British Columbia, Vancouver, BC; Vancouver Island Health Authority (Hodson), Comox, BC; BC Patient Safety and Quality Council (Hodson), Vancouver, BC

Contributors: Julie Bettinger, Devon Greyson and Richard Carpiano contributed substantially to the conception and design, acquisition of data, and analysis and interpretation of data. Pamela de Bruin, Issy Aguiar, Monika Naus and Brett Hodson contributed substantially to the conception and design. Julie Bettinger wrote the manuscript, which the other authors revised critically for important intellectual content. All authors gave final approval of the version to be published and agreed to act as guarantors of the work.

Funding: This study was funded by the British Columbia Immunization Committee, a subcommittee of the Communicable Disease Policy Committee.

Supplemental information: For reviewer comments and the original submission of this manuscript, please see www.cmajopen.ca/content $/ 7 / 2 /$ E264/suppl/DC1. 